\title{
Komitmen Organisasi dalam Perspektif Alkitabiah: Sebuah Studi Kuantitatif di Yayasan C Surabaya
}

\author{
Sonny Eli Zaluchu \\ Sekolah Tinggi Teologi Baptis Semarang \\ gloryofgodmin@gmail.com
}

\begin{abstract}
Commitment in the organization consists of three, namely affective commitment, continuous commitment, and normative commitment. This commitment can develop with training in professionalism and the planting of Christian values. This study aims to see the extent to which organizational commitment is practice in a Christian foundation by leaders who are directly responsible for running the organization and to find out what spiritual value is the most active form of that commitment. The study was conducted quantitatively using a questionnaire as a data collector. Data is processed to find the position of the confidence interval values in the interval class (high, medium and low). The results of the study show that the dominant commitment affecting unit leaders at the foundation is a continuous commitment which in a biblical perspective is called a hired servant.
\end{abstract}

Keywords: affective commitment; commitment; continuous commitment; normative commitment; organizational commitment; performance

\begin{abstract}
Abstrak
Komitmen di dalam organisasi terdiri dari tiga yakni komitmen afektif, komitmen kontinuans dan komitmen normatif. Komitmen ini dapat dikembangkan dengan pelatihan profesionalisme dan penanaman nilai-nilai kristiani. Penelitian ini bertujuan untuk melihat sejauh mana komitmen organisasi dipraktekan di dalam sebuah yayasan Kristen oleh para pemimpin yang bertanggung jawab langsung dalam menjalankan roda organisasi dan untuk menemukan nilai rohani apa yang paling kuat membentuk komitmen tersebut. Penelitian dilakukan secara kuantitatif menggunakan angket sebagai pengumpul data. Data diolah untuk menemukan posisi nilai interval kepercayaan di dalam klas interval (tinggi, sedang dan rendah). Hasil penelitian memperlihatkan, bahwa komitmen yang dominan mempengaruhi para pemimpin unit di yayasan tersebut adalah komitmen kontinuans yang dalam perspektif Alkitabiah disebut sebagai hamba upahan.
\end{abstract}

Kata Kunci: komitmen; kinerja; komitmen afektif; komitmen kontinuans; komitmen normatif; komitmen organisasi 


\section{PENDAHULUAN}

Penelitian yang dilakukan oleh Meyer et.al. membuktikan bahwa terdapat korelasi yang positif dan signifikan antara persepsi guru mengenai pemberdayaan mereka (teacher empowerment) dalam membangun komitmen terhadap organisasi dan profesi keguruan ${ }^{1}$. Temuan tersebut membuktikan bahwa komitmen bukanlah sesuatu yang muncul serta merta. Diperlukan upaya, proses dan langkah-langkah tertentu agar komitmen terbentuk. Hal tersebut dikuatkan oleh temuan Nurandini dan Lataruva, bahwa komitmen terhadap organisasi ternyata erat kaitannya dengan kinerja pekerja ${ }^{2}$. Artinya dimana komitmen terhadap organisasi terbentuk, maka dengan sendirinya kinerja pekerja di dalam organisasi tersebut juga meningkat secara signifikan.

Bukan hal yang mudah untuk membentuk komitmen di dalam organisasi sebagai sebuah budaya yang harus dikembangkan dan ditumbuhkebangkan. Terlebih jika organisasi mencakup dan melibatkan karyawan yang sangat besar, di dalam unit-unit yang berbeda, sebagaimana di organisasi Yayasan C Surabaya, yang berfokus penyelenggaraan pendidikan, mulai dari TK, SD, SMP hingga SMA, yang proses pembelajarannya berazaskan nilai-nilai kristiani. Sangat penting untuk mengetahui apakah di kalangan karyawan yayasan tersebut, khususnya kalangan pemimpin (leader), memiliki komitmen organisasi yang dibangun berdasarkan azas Kristiani, dan nilai kekristenan seperti apakah yang dominan mempengaruhi. Kesimpulan yang dibuat oleh Kelman dan Hong dalam penelitian, mengutip teori yang pernah dikemukakan oleh Hambrick \& Mason tentang "teori eselon atas", menyebutkan bahwa perubahan di dalam sebuah organisasi yang paling bermanfaat hanya dapat terjadi dengan membentuk perilaku dari para manajer puncak organisasi tersebut ${ }^{4}$. Sebab perilaku tersebut berdampak secara signifikan terhadap kinerja sebuah organisasi. Itu sebabnya di dalam penelitian ini, sasaran utama penelitian adalah para pemimpin unit yang terkait langsung dengan kebijakan, keputusan dan pelaksanaan organisasi.

\footnotetext{
${ }^{1}$ John P. Meyer et al., "Affective, Continuance, and Normative Commitment to the Organization: A Meta-Analysis of Antecedents, Correlates, and Consequences," Journal of Vocational Behavior, 2002.

${ }^{2}$ Nurandini, A., \& Lataruva, E., “Analisis Pengaruh Komitmen Organisasi Terhadap Kinerja Karyawan (Studi Pada Pegawai Perum PERUMNAS Jakarta),” Jurnal Studi Manajemen \& Organisasi 11 11 (2014): 79.

${ }^{3}$ D. C. Hambrick and P. A. Mason, "Upper Echelons: The Organization as a Reflection of Its Top Managers.," Academy of Management Review 9, no. 2 (1984): 193-206, http://amr.aom.org/cgi/doi/10.5465/AMR.1984.4277628.

${ }^{4}$ Steven Kelman and Sounman Hong, "This Could Be the Start of Something Big: Linking Early Managerial Choices with Subsequent Organizational Performance," Journal of Public Administration Research and Theory 25, no. 1 (2015): 135-164. DOI: 10.1093/jopart/muu010
} 
Berdasarkan latar belakang itulah maka penelitian ini dilakukan dengan mengangkat tema tentang kecenderungan komitmen organisasi dalam perspektif alkitabiah perangkat pimpinan unit penyelenggaran pendidikan di Yayasan C Surabaya.

\section{Komitmen Organisasi}

Merujuk pada definisi komitmen di dalam Dictionary of Human Resources and Personal Management, menyebutkan bahwa arti kata kerja commit sebagai akar kata commitment, salah satunya berarti untuk setuju melakukan sesuatu (untuk kepentingan tertentu). Sementara kata benda commitment sendiri diartikan sebagai sesuatu yang telah disetujui untuk dilakukan (misalnya dalam perusahaan) ${ }^{5}$. Definisi tersebut sejalan dengan ungkapan Locke yang menyebutkan komitmen sebagai sikap antusiasme seseorang, sehingga melaluinya individu tersebut dapat bekerja maksimum dan efektif. ${ }^{6}$ Lebih jelas lagi di dalam definisi yang dikemukakan oleh Santrock, bahwa komitmen berhubungan langsung dengan cara seseorang mengerjakan sesuatu. ${ }^{7}$

Dari berbagai definisi tersebut di atas, dapat disimpulkan bahwa komitmen adalah bagian dari sikap seseorang yang memperlihatkan keterlibatan dan persetujuan terhadap sesuatu hal, yang dinyatakan di dalam perilaku mendukung, bekerja keras, melakukan yang terbaik, memenuhi kewajiban, baik kepada orang, lembaga, atau dalam mencapai tujuan tertentu. Komitmen memiliki dua aspek sekaligus yakni sikap (attitude) dan perilaku (behavior).

Salah satu dampaknya disimpulkan dari hasil penelitian Aronson, yaitu komitmen membuat karyawan lebih konsisten dalam perilaku dan caranya bertindak. ${ }^{8}$ Hasil penelitian ini dapat menjelaskan hubungan komitmen dengan pencapaian tujuan organisasi. Apabila setiap individu dalam organisasi rendah komitmennya, maka tujuantujuan mulia organisasi akan terlantar. Manajemen organisasi akan kacau.

Dengan demikian, pentingnya komitmen di dalam organisasi, mengarah pada sebuah gambaran nyata, bahwa organisasi dikatakan berhasil apabila organisasi tersebut bukan saja mampu mencapai tujuan-tujuannya, tetapi juga mampu menggerakkan seluruh sumber daya dan kompetensi yang ada di dalam diri setiap orang yang terlibat dalam

\footnotetext{
${ }^{5}$ Dictionary of Human Resources and Personal Management (London: A\&C Black Publisher, 2003), 51.

${ }^{6}$ Edwin Locke, ed., Handbook of Principles of Organizational Behavior (Oxford, United Kingdom: Blackwell, 2003), 6.

${ }^{7}$ John W. Santrock, Life-Span Development (Dubuque, IA: Brown \& Benchmark Publishers, 1997), 400.

${ }^{8}$ Stuart Oskamp and P. Wesley Schultz, Attitudes and Opinions (London: Lawrence erlbaum Associates Publisher, 2005), 265.
} 
organisasi menurut tanggung jawabnya masing-masing. Hal tersebut didefenisikan Robbins \& Langton sebagai komitmen organisasional. Artinya: a state in which an employee identifies with a articular organization and its goals, and wishes to maintain membership in the organization. ${ }^{9}$

\section{Tipologi Komitmen Organisasi}

Konsep terinci tentang jenis jenis komitmen dideskripsikan oleh Allen \& Meyer sebagai hasil dari penelitian mereka mengenai komitmen pada organisasi. ${ }^{10}$ Allen \& Meyer membagi tiga jenis komitmen organisasi ${ }^{11}$ sebagaimana diuraikan berikut ini.

\section{Komitmen Afektif (Affective Commitment)}

Komitmen Afektif didefinisikan sebagai komitmen dimana individu memiliki hasrat yang kuat untuk tetap bekerja pada organisasi karena sependapat dengan tujuan dan nilai-nilai organisasi. Hal ini sejalan dengan pendapat Greenberg yang melihat bahwa komitmen ini terbentuk akibat selarasnya tujuan dan visi organisasi dengan individu. Selengkapnya:

The strength of people's desire to continue working for an organization because they agree with its underlying goals and values. People feeling high degrees of affective commitment desire to remain in their organizations because they endorse that the organization stands for and are willing to help it in its mission. ${ }^{12}$

Sejalan dengan itu, Robbins \& Langton juga sependapat dengan mengatakan, komitmen afektif sebagai: Which describes the strength of individual's emotional attachment, to identification with, and involvement in the organization. ${ }^{13}$ Artinya, secara emosional seorang individu terikat dengan organisasinya.

Penerimaan terhadap tujuan organisasi membentuk keterikatan psikologis di dalam individu terhadap organisasinya. Keterikatan tersebut memberi pengaruh positif pada perilaku terhadap setiap tugas yang diemban. Perilaku yang dimaksud adalah tindakan penyelesaian tugas dengan baik, kesukaan bahkan gairah dalam menjalankan tugas, tingginya dedikasi dan loyalitas.

\footnotetext{
${ }^{9}$ Stephen P Robbins and Nancy Langton, Organizational Behavior (Canada: Pearson Education Canada, 2003), 88.

${ }^{10}$ Natalie J. Allen and John P. Meyer, "The Measurement and Antecedents of Affective, Continuance and Normative Commitment to the Organization," Journal of Occupational Psychology 63, no. 1 (1990): 1-18.

${ }^{11}$ John P. Meyer and Natalie J. Alien, "A Three-Component Conceptualization of Organizational Commitment," Human Resource Management Review 1, no. 1 (1991): 61-89.

12 Jerald Greenberg, Managing Behavior in Organizations, ed. Inc. Prentice-Hall (Upper Sadle River, NJ, 1996), 105.

${ }^{13}$ Robbins and Langton, Organizational Behavior, 10.
} 
Prinsip totalitas diungkapkan sangat deskriptif oleh Rasul Paulus kepada jemaat Kolose. Dikatakan oleh Paulus, apapun juga yang kamu perbuat, perbuatlah dengan segenap hatimu seperti untuk Tuhan dan bukan untuk manusia (Kolose 3:23). Disitu Paulus sengaja menggunakan kata psyches untuk mendeskripsikan konsep segenap hati. Kata itu mencukup pengertian kehidupan secara total, pikiran bahkan jiwa, untuk segala hal yang dikerjakan. ${ }^{14}$ Apalagi di dalam ayat tersebut Paulus merujuk tentang 'perbuatan' menyangkut pekerjaan, maka sebagaimana komitmen Afektif maksudkan, dedikasi pekerjaan ditujukan kepada Tuhan, bukan kepada manusia. Segala hal yang dilakukan kepada Tuhan adalah hal terbaik.

\section{Komitmen Kontinuans (Continuance Commitment)}

Komitmen Kontinuans didefinisikan sebagai keterikatan individu untuk tetap bekerja bagi organisasi karena adanya sejumlah investasi seperti waktu, usaha, pertemanan, dan sejumlah keuntungan (benefits) yang harus dikorbankan bila meninggalkan organisasi. Terlihat dalam pendapat Greenberg yang mengatakan, "The strength of a person's desire to remain working for an organization due to his or her belief that it may be costly to leave...many people are commited to staying on their job simply because they are unwilling to risk losing these things."15

Dalam hal ini, bentuk komitmen kontinuans lebih ditekankan pada kepentingan atau kerugian yang akan dialami individu apabila meninggalkan organisasinya. Dalam hal ini, individu membangun komitmen karena membutuhkan organisasi. Beberapa hal yang dapat membuat seorang individu bertahan di dalam organisasi adalah menerima imbalan gaji yang tinggi dari organisasi. Nominal yang sama belum tentu didapatkan dari tempat lain. Juga karena sejumlah fasilitas yang selama ini dinikmati seperti kebutuhan primer, kendaraan, dana pendidikan, kebutuhan rumah tangga, jaminan kesehatan, dsb. Selain hal-hal material tersebut, bertahannya individu di dalam organisasi juga dapat disebabkan oleh pengaruh dan posisi yang diberikan organisasi kepadanya lewat jabatan atau kedudukan tertentu. Maka, agar semuanya dapat terus dinikmati, maka individu mempertahankan komitmennya kepada organisasi secara kontinuans.

Alkitab menyebut konsep ini sebagai 'hamba upahan' yang kesetiaan dan komitmennya diperoleh berdasarkan gaji yang diterima. Di dalam Yohanes 10:11-13 muncul narasi tentang perbandingkan gembala sejati dengan gembala upahan. "Akulah gembala yang baik. Gembala yang baik memberikan nyawanya bagi domba-

${ }^{14}$ Marvin R. Vincent, Word Studies in The New Testament Volume 3,4 (Albani, Oregon: SAGE Software, 1996), 546.

${ }^{15}$ Greenberg, Managing Behavior in Organizations, 104. 
dombanya; sedangkan seorang upahan yang bukan gembala, dan yang bukan pemilik domba-domba itu sendiri, ketika melihat serigala datang, meninggalkan domba-domba itu lalu lari, sehingga serigala itu menerkam dan mencerai-beraikan domba-domba itu. Ia lari karena ia seorang upahan dan tidak memperhatikan domba-domba itu." Gembala sejati berani mempertaruhkan nyawa melindungi domba-dombanya sedangkan gembala upahan dapat lari menyelamatkan dirinya sendiri dengan mengorbankan domba-domba yang seharusnya dijaganya. Komitmen gembala upahan hanya terbentuk dan bergantung dari upah yang diterimanya. Itu sebabnya dalam deskripsi komitmen kontinuans, selalu terbuka kemungkinan seseorang meninggalkan pekerjaannya yang lama dan membangun komitmen baru di lingkup pekerjaan baru yang lebih menjanjikan upah dan fasilitas.

\section{Komitmen Normatif (Normative Commitment)}

Komitmen Normatif bersifat sangat subjektif karena merupakan aspek perasaan individu. Perasaan tersebut muncul kerena berada di dalam tekanan orang lain terutama mengenai apa yang akan orang katakan jiwa mereka meninggalkan organisasi. Komitmen ini juga menjelaskan perasaan karyawan mengenai kewajiban dan tanggungjawab moral yang harus diberikan kepada organisasi. Hal tersebut didukung oleh pendapat Greenberg yang mengatakan, "This refers to employees feelings of obligation to stay with the organization because of pressures from others. People who have high degrees of normative commitment are greatly concerned about what others would think of them for leaving. ",16

Komitmen ini berkembang sebagai hasil dari pengalaman sosialisasi, tergantung dari sejauh mana perasaan kewajiban itu terbentuk di dalam diri individu. Dalam komitmen ini terdapat sejumlah faktor yang membuat individu mengembangkan perasaan terikat pada organisasi seperti ikatan moral, ikatan keagamaan, ikatan sosial, ikatan sejarah, sentimen denominasional atau ikatan kekeluargaan. Ikatan jasa juga termasuk didalamnya. Faktor-faktor tersebut, menggunakan istilah Greenberg, dapat menjadi semacam social pressure bagi seorang individu untuk tetap berada dalam organisasi. ${ }^{17}$ Hal ini terjadi karena ikatan sosial antar-pekerja telah terbentuk. Pengalaman Nuh dan anak-anaknya dapat menjadi contoh. Dalam Kejadian 7:7 dikatakan, "Masuklah Nuh ke dalam bahtera itu bersama-sama dengan anak-anaknya dan isterinya dan isteri anakanaknya karena air bah itu." Visi untuk membangun bahtera bukan pada anak isterinya melainkan pada Nuh. Ikatan kekeluargaan dan kepentingan membuat kelompok kecil ini

\footnotetext{
${ }^{16}$ Ibid., 105.

${ }^{17}$ Ibid., 104.
} 
membangun komitmen bersama untuk masuk ke dalam bahtera dan akhirnya terlibat di dalam rencana Tuhan atas bumi.

\section{METODE PENELITIAN}

Penelitian ini tergolong di dalam jenis penelitian kuantitatif eksplanatori yang datanya diperoleh dengan metode survey berupa angket berskala Likert. Survey dilakukan untuk mengkaji kecenderungan variabel Y dan indikator-indikator penyusunnya melalui hubungan endogenous dan eksogenous variabel. Populasi penelitian adalah seluruh pimpinan unit yang ada di dalam organisasi Yayasan Pendidikan Kristen C yang berdomisili di Surabaya, yang terdiri dari Kepala dan Wakil Kepala Sekolah, Kepala Bagian dan kepala unit-unit lain dalam organisasi Yayasan tersebut. Penelitian diarahkan untuk melihat kecenderungan variabel utama $\mathrm{Y}$ yakni komitmen organisasi para pemimpin unit di yayasan tersebut.

Hubungan antar-variabel mengikuti hubungan endogenous dan eksogenous variabel. ${ }^{18}$ Hal ini terjadi karena tiga unsur komitmen yang menjadi indikator yakni komitmen afektif $\left(\mathrm{I}_{1}\right)$, komitmen kontinuans $\left(\mathrm{I}_{2}\right)$ dan komitmen normatif $\left(\mathrm{I}_{3}\right)$ adalah variabel eksogenous (penyusun atau pembentuk) bagi komitmen organisasi (Y) sebagai variabel endogenous. Variabel eksogenous adalah variabel yang keragamannya berada di luar model dan yang berperan untuk menjelaskan variabel-variabel lain atau hasil dalam model atau disebut juga variabel bebas. Sementara variabel endogenous adalah variabel yang disebabkan oleh satu atau lebih variabel dalam model atau disebut juga variabel terikat. $^{19}$

Analisis dilakukan dengan menghitung nilau $\mu$ (confidence interval) dan menempatkannya di dalam klas interval untuk menentukan kecenderungan komitmen. Ditetapkan tiga kategori kecenderungan yakni tinggi, sedang dan rendah. Analisis dilanjutkan untuk memperoleh nilai Standardized Coefficients Beta untuk melihat indikator tersebut yang pengaruhnya paling dominan di dalam model. Perhitungan dilakukan dengan metode parametrik setelah menghitung deviation from linearity memenuhi standar linier pada nilai $\alpha>0.05^{20}$. Semua variabel di dalam penelitian ini ditetapkan dalam asumsi homogen.

\footnotetext{
${ }^{18}$ Benjamin M. Bolker, "Combining Endogenous and Exogenous Spatial Variability in Analytical Population Models," Theoretical Population Biology 64, no. 3 (2003): 255-270.

${ }^{19}$ Johan Wagemans, "Cognitive Psychology," ed. Kimberly Kempf-Leonard, Encyclopedia of Social Measurement (2005): 351-359, http://linkinghub.elsevier.com/retrieve/pii/B0123693985004801.

${ }^{20}$ Sonny Eli Zaluchu, Sistematika Riset Dan Analisis Data Kuantitatif, 2nd ed. (Semarang: Golden Gate Publishing, 2018), 81-82.
} 


\section{HASIL DAN PEMBAHASAN}

Hasil perhitungan statistik deskriptif untuk menghitung kecenderungan dari $\mathrm{Y}$ yakni komitmen organisasi dalam perspektif Alkitabiah perangkat pimpinan unit penyelenggaran pendidikan di Yayasan C Surabaya disajikan pada tabel di bawah ini.

Tabel 1: Hasil Uji Descriptive Statistics variabel Y

(Komitmen Organisasi dalam perspektif Alkitabiah

Perangkat Pimpinan Unit Penyelenggaran

Pendidikan di Yayasan C Surabaya)

\begin{tabular}{|c|c|c|c|}
\hline Total Descriptive & & Statistic & $\begin{array}{c}\text { Std. } \\
\text { Error }\end{array}$ \\
\hline Mean & & 54.67 & 1.116 \\
\hline \multirow[t]{2}{*}{ 95\% Confidence Interval } & $\begin{array}{l}\text { Lower } \\
\text { Bound }\end{array}$ & 52.27 & \\
\hline & $\begin{array}{l}\text { Upper } \\
\text { Bound }\end{array}$ & 57.06 & \\
\hline $\begin{array}{l}5 \% \text { Trimmend } \\
\text { Mean }\end{array}$ & & 54.63 & \\
\hline Median & & 55.00 & \\
\hline Variance & & 18.667 & \\
\hline Std. Deviation & & 4.320 & \\
\hline Minimum & & 47 & \\
\hline Maximum & & 63 & \\
\hline Range & & 16 & \\
\hline Interquartile Range & & 6 & \\
\hline Skewness & & .361 & .580 \\
\hline Kurtosis & & .086 & 1.121 \\
\hline
\end{tabular}

Dari tabel di atas diperoleh $\mathrm{R}$ sebesar 16. Berdasarkan penetapan Jumlah klas $\left(\sum \mathrm{k}\right)$ sebanyak 3, maka diperoleh nilai 5.3 dan ditetapkan 5. Dengan nilai minimum sebesar 47 dan maksimun 63, maka kecenderungan Komitmen Organisasi dalam perspektif Alkitabiah Perangkat Pimpinan Unit Penyelenggaran Pendidikan di Yayasan C Surabaya dapat dilihat pada tabulasi di bawah ini. 
Tabel 2. Hasil Analisis Kecenderungan Komitmen Organisasi dalam perspektif Alkitabiah Perangkat Pimpinan Unit Penyelenggaran Pendidikan di Yayasan C Surabaya

\begin{tabular}{ccc}
\hline $\begin{array}{c}\text { Klas } \\
\text { Interval }\end{array}$ & Kecenderungan & $\begin{array}{c}\text { Rentang Confidence } \\
\text { Interval }\end{array}$ \\
\hline $46-51$ & Rendah & \\
\hline $52-57$ & Sedang & $\mathbf{5 2 . 2 7}$ s/d 57.06 \\
\hline $58-63$ & Tinggi & \\
\hline
\end{tabular}

Berdasarkan tabel tersebut rentang nilai Confidence Interval adalah dalam kategori sedang. Dengan demikian dapat disimpulkan bahwa Komitmen Organisasi dalam perspektif Alkitabiah Perangkat Pimpinan Unit Penyelenggaran Pendidikan di Yayasan C Surabaya berada di dalam kategori sedang.

Hasil perhitungan latar belakang responden yang dominan mempengaruhi Komitmen Organisasi dalam perspektif Alkitabiah Perangkat Pimpinan Unit Penyelenggaran Pendidikan di Yayasan C Surabaya diperlihatkan melalui gambar perhitungan C\&RT berikut ini. 
Tabel 3: Hasil Perhitungan C\&RT

Kategori Latar Belakang Dominan yang mempengaruhi

Komitmen Organisasi dalam perspektif Alkitabiah Perangkat Pimpinan Unit

Penyelenggaran Pendidikan di Yayasan C Surabaya

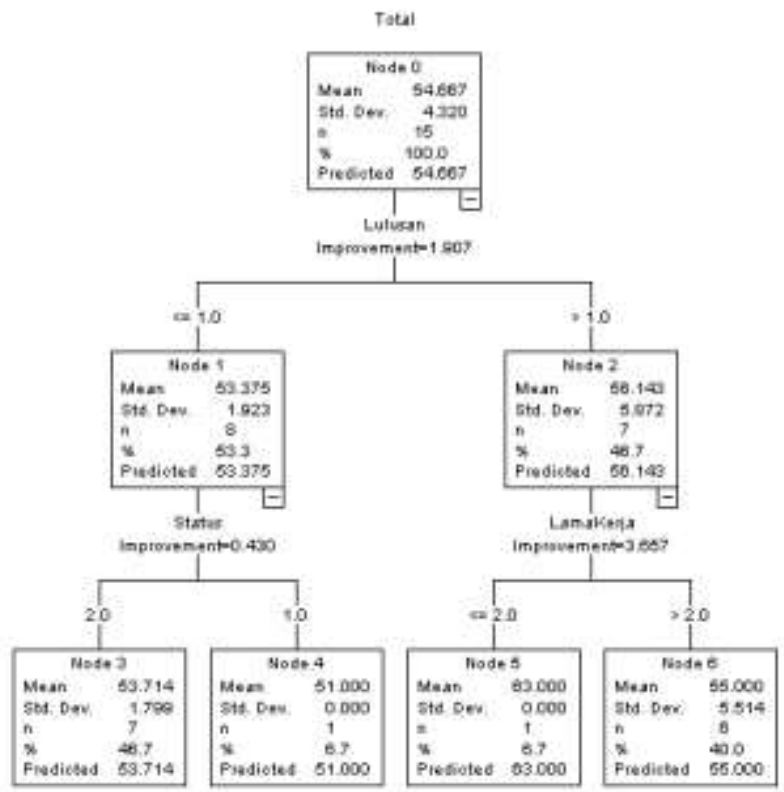

Berdasarkan hasil perhitungan tersebut, maka kategori latar belakang yang dominan mempegaruhi komitmen organisasi adalah profil lulusan, melebihi kategori status pernikahan dan masa kerja. Terdapat tiga profil lulusan pimpinan unit yakni lulusan S1, S2 dan S3. Analisis mean terhadap ketiga profil tersebut adalah sebagai berikut.

Tabel 4: Hasil Analisis Mean Kategori Profil Lulusan

\begin{tabular}{ccccc}
$\begin{array}{l}\text { Kategori } \\
\text { Lulusan }\end{array}$ & N & Mean & $\begin{array}{c}\text { Std. } \\
\text { Deviation }\end{array}$ & $\begin{array}{c}\text { Std. } \\
\text { Error }\end{array}$ \\
\hline S1 & 8 & 53.38 & 1.923 & .680 \\
\hline S2 & 6 & 56.00 & 6.419 & 2.620 \\
\hline S3 & 1 & 57.00 &. &. \\
\hline Total & 15 & 54.67 & 4.320 & 1.116 \\
\hline
\end{tabular}


Dengan melihat hasil analisis di atas, sekalipun jumlah terbanyak dari pimpinan unit adalah lulusan S1, tetapi profil lulusan dari jenjang S3 yang dominan mempengaruhi komitmen organisasi seluruh pimpinan unit di Yayasan C Surabaya dengan nilai mean tertinggi yaitu 57.00. Peringkat kedua adalah profil lulusan S2 dengan mean 56.00. Artinya, komitmen organisasi dalam perspektif Alkitabiah di Yayasan Pendidikan C Surabaya dipengaruhi oleh profil lulusan para pimpinan unit dalam hal ini telah menempuh pendidikan di level pascasarjana.

Hasil uji serentak komitmen afektif, komitmen kontinuans dan komitmen normatif terhadap komitmen organisasi dalam perspektif Alkitabiah diperoleh data sebagaimana tabel di bawah ini.

\section{Tabel 5:}

Hasil Uji Serentak Semua Indikator Komitmen terhadap Komitmen Organisasi dalam perspektif Alkitabiah Perangkat Pimpinan Unit Penyelenggaran Pendidikan di Yayasan $\mathrm{C}$

\begin{tabular}{rccc}
\hline \multirow{2}{*}{ Model } & \multicolumn{2}{c}{$\begin{array}{c}\text { Unstandardized } \\
\text { Coefficients }\end{array}$} & $\begin{array}{c}\text { Standardized } \\
\text { Coefficients }\end{array}$ \\
\cline { 2 - 4 } & B & Std. Error & Beta \\
\hline (Constant) & $1,06 \mathrm{E}-11$ & .000 & \\
\hline K. Afektif & 1.000 & .000 & .615 \\
\hline K. Kontinuans & 1.000 & .000 & .700 \\
\hline K. Normatif & 1.000 & .000 & .642 \\
\hline
\end{tabular}

Temuan uji serentak tersebut dikuatkan dengan analisis C\&RT yang hasilnya ditampilkan pada tabel di bawah ini. 
Tabel 6: Hasil Uji Serentak Semua Indikator Komitmen terhadap Komitmen Organisasi dalam perspektif Alkitabiah Perangkat Pimpinan Unit Penyelenggaran Pendidikan di Yayasan C menggunakan teknik C\&RT

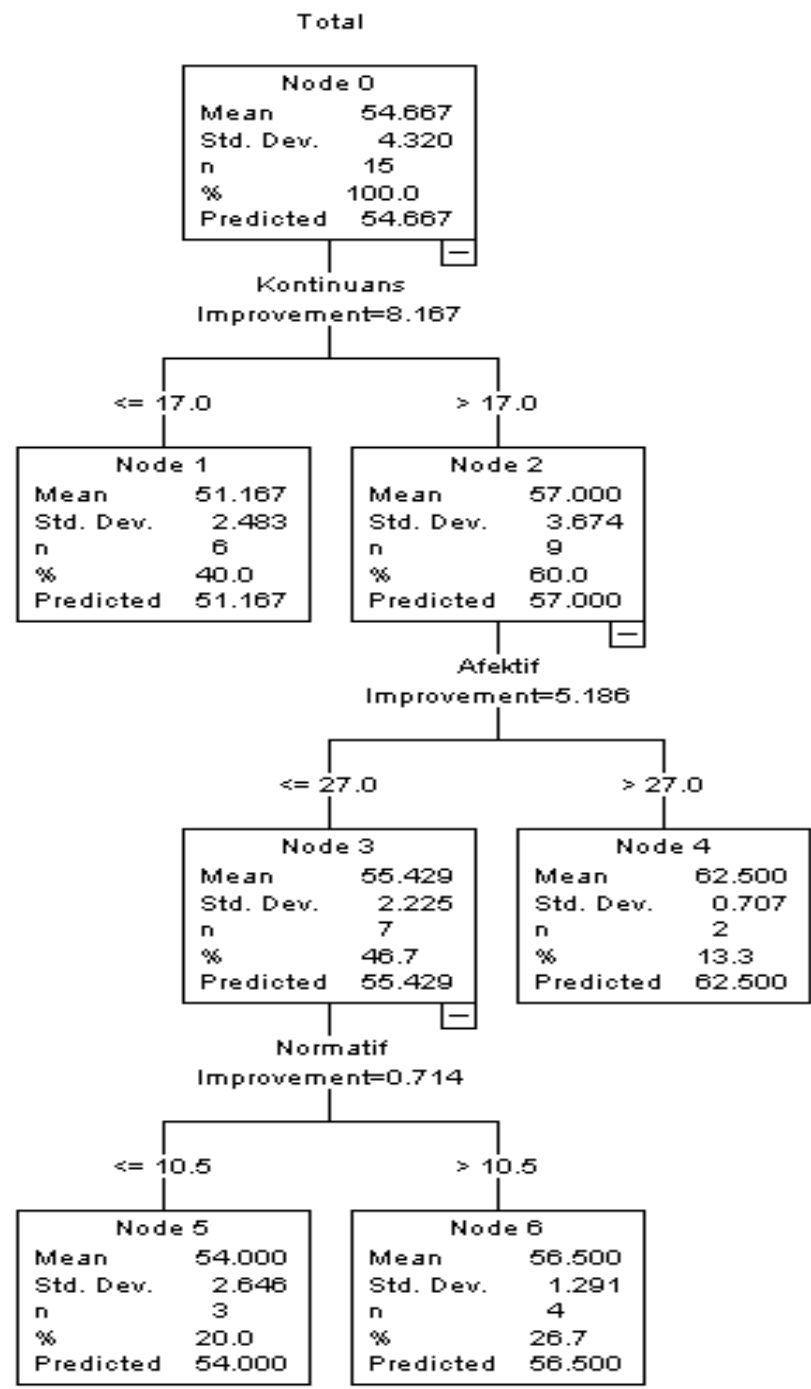

Dari data tersebut diperoleh hasil bahwa komitmen kontinuans adalah yang dominan mempengaruhi komitmen organisasi dalam perspektif Alkitabiah seluruh pimpinan unit di Yayasan C Surabaya. Kedua alat analisis memberikan hasil yang sama, baik melalui uji nilai Beta maupun dengan uji C\&RT, komitmen kontinuans adalah yang paling besar pengaruhnya membentuk komitmen organisasi seluruh pimpinan unit penyelenggaran pendidikan di Yayasan C Surabaya. 


\section{KESIMPULAN}

Berdasarkan uraian teoritis, sekalipun memiliki nilai-nilai Kristiani di dalam pekerjaan dan pelayanan, para pimpinan unit di Yayasan C Surabaya tetap memperhitungkan aspek keuntungan yang diperoleh dari organisasi atas pekerjaan yang dilakukan di yayasan tersebut. Ditemukannya fata bahwa komitmen kontinuans adalah faktor dominan yang membentuk komitmen para pemimpin, membuktikan uraian teoritis mengenai komitmen tersebut. Dapat disimpulkan bahwa seluruh responden adalah pimpinan unit yang memiliki dan menikmati sejumlah fasilitas melebihi karyawan biasa, sehingga mempertahankan komitmen terhadap organisasi akan membawa keuntungan secara pribadi. Bahaya dari menguatnya jenis komitmen ini, adalah kesetiaan terhadap organisasi hanya ditentukan oleh keuntungan dan bukan pada visi misi. Dengan sendirinya, apabila terdapat hal yang lebih menguntungkan dari organisasi lain, maka responden berpotensi untuk meninggalkan pekerjaannya di Yayasan C Surabaya dan pindah ke tempat pekerjaan baru yang dianggap lebih membawa keuntungan. Dalam persepektif rohani, dapat disimpulkan bahwa mayoritas pimpinan unit di yayasan tersebut tergolong sebagai hamba upahan di dalam organisasi.

Jika dilihat secara keseluruhan, komitmen organisasi dalam perspektif Alkitabiah seluruh pimpinan unit di Yayasan C Surabaya berada di dalam kategori sedang. Faktor latar belakang yang dominan mempengaruhi komitmen ini adalah profil lulusan dalam hal ini lulusan pasca-sarjana. Artinya komitmen ini masih memiliki peluang untuk ditingkatkan dari sedang menuju tinggi. Salah satu caranya adalah memberikan treatment kepada seluruh pimpinan unit di Yayasan C Surabaya tentang nilai-nilai kristiani yang mengajarkan aspek pelayanan, totalitas dan kehambaan. Usaha ini dapat dilakukan

melalui retret, penanaman nilai-nilai melalui pertemuan ibadah rutin dan pendekatan personal.

\section{REFERENSI}

Allen, Natalie J., and John P. Meyer. "The Measurement and Antecedents of Affective, Continuance and Normative Commitment to the Organization." Journal of Occupational Psychology 63, no. 1 (1990): 1-18.

Bolker, Benjamin M. "Combining Endogenous and Exogenous Spatial Variability in Analytical Population Models." Theoretical Population Biology 64, no. 3 (2003): 255-270.

Greenberg, Jerald. Managing Behavior in Organizations. Edited by Inc. Prentice-Hall. Upper Sadle River, NJ, 1996. 
Hambrick, D. C., and P. A. Mason. "Upper Echelons: The Organization as a Reflection of Its Top Managers.” Academy of Management Review 9, no. 2 (1984): 193-206. http://amr.aom.org/cgi/doi/10.5465/AMR.1984.4277628.

Kelman, Steven, and Sounman Hong. "This Could Be the Start of Something Big: Linking Early Managerial Choices with Subsequent Organizational Performance." Journal of Public Administration Research and Theory 25, no. 1 (2015): 135-164.

Locke, Edwin, ed. Handbook of Principles of Organizational Behavior. Oxford, United Kingdom: Blackwell, 2003.

Meyer, John P., and Natalie J. Alien. "A Three-Component Conceptualization of Organizational Commitment." Human Resource Management Review 1, no. 1 (1991): 61-89.

Meyer, John P., David J. Stanley, Lynne Herscovitch, and Laryssa Topolnytsky. "Affective, Continuance, and Normative Commitment to the Organization: A Meta-Analysis of Antecedents, Correlates, and Consequences." Journal of Vocational Behavior, 2002.

Nurandini, A., \& Lataruva, E. "Analisis Pengaruh Komitmen Organisasi Terhadap Kinerja Karyawan (Studi Pada Pegawai Perum PERUMNAS Jakarta).” Jurnal Studi Manajemen \& Organisasi 1111 (2014): 79.

Oskamp, Stuart, and P. Wesley Schultz. Attitudes and Opinions. London: Lawrence erlbaum Associates Publisher, 2005.

Robbins, Stephen P, and Nancy Langton. Organizational Behavior. Canada: Pearson Education Canada, 2003.

Santrock, John W. Life-Span Development. Dubuque, IA: Brown \& Benchmark Publishers, 1997.

Vincent, Marvin R. Word Studies in The New Testament Volume 3,4. Albani, Oregon: SAGE Software, 1996.

Wagemans, Johan. "Cognitive Psychology." Edited by Kimberly Kempf-Leonard. Encyclopedia of Social Measurement (2005): 351-359. http://linkinghub.elsevier.com/retrieve/pii/B0123693985004801.

Zaluchu, Sonny Eli. Sistematika Riset Dan Analisis Data Kuantitatif. 2nd ed. Semarang: Golden Gate Publishing, 2018.

Dictionary of Human Resources and Personal Management. London: A\&C Black Publisher, 2003. 